\title{
Comparative Study on the Psychoactive Effects of Nicotine and Cotinine
}

\author{
ANA MARIA VLASCEANU ${ }^{1}$, CORNEL CHIRITA ${ }^{1 *}$, DRAGOS MIHAI ${ }^{1}$, CRISTINA DANIELA MARINECI ${ }^{1}$, MIRIANA STAN ${ }^{1}$, \\ CRISTIAN BALALAU ${ }^{2}$, DANIELA GRADINARU ${ }^{1}$, DANIELA BACONI ${ }^{1}$ \\ ¿University of Medicine and Pharmacy Carol Davila, Faculty of Pharmacy, 6 Traian Vuia Str., 020956, Bucharest, Romania \\ ZUniversity of Medicine and Pharmacy Carol Davila, Faculty of General Medicine, St. Pantelimon Emergency Hospital, \\ 340-342 Pantelimon Road, 021623, Bucharest, Romania
}

\begin{abstract}
Nicotine and its main metabolite cotinine have been suggested to have psychoactive properties in humans and animals. The present study aims to investigate comparatively the psychoactive profile, as antidepressant and anxiolytic effects, of cotinine and nicotine in NMRI mice. The animalswere orally treated with nicotine $(0.5 \mathrm{mg} / \mathrm{kg}$ ) and cotinine (5 mg/kg) for 14 days. Pharmacological tests (forced swimming test (FST) and tail suspension test (TST) for the antidepressant activity, as well as elevated maze testfor the anxiolytic activity) were performed after 1, 7 and 14 days. Imipramine $(25 \mathrm{mg} / \mathrm{kg}$ ) was used as a control for the antidepressant activity. Imipramine and cotinine bothexerted comparable and statistically significant antidepressant effectsafter 7 days of treatment, while no effect was observedin the animals treated with nicotine. An important anxiogenic effect was revealed for imipramine after 14 days treatment. Nicotine was shown to have an axiolytic effect after 14 days treatment. The study highlighted some psychotropic effects of nicotine and cotinine in mice, depending on the treatment regimen.
\end{abstract}

Keywords: nicotine, cotinine, antidepressant activity, anxiolytic effects

Having in view the high incidence of smoking amongst individuals with psychiatric conditions including depression, bipolar disorder, and schizophrenia the hypothesis of selfmedication with nicotine in some of these patients has been postulated [1-2].

Until recently cotinine was considered an inactive nicotine metabolite (fig. 1) and has been used primarily as biomarker of smoking, including passive smoking and as an indication of smoking cessation compliance $[3,4,18]$.

Current evidence convincingly argues that cotinine is an active metabolite, with actions indicating that it may mediate some of the beneficial psychoactive effects of nicotine but also with unique properties.

Despite the structural similarity between nicotine and cotinine, the metabolite shows distinctive effects from nicotine.In the last decades, studies have been focused on the pharmacological effects of nicotine and its main metabolite cotinine.

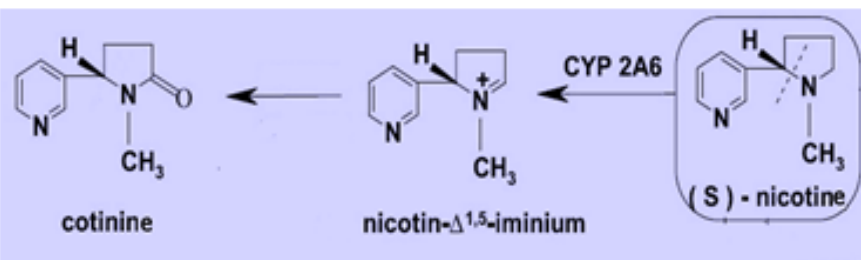

Fig.1. Biotransformation of nicotine to cotinine [8]

Cotinine, the main metabolite of nicotine was shown to exert measurable effects on certaintypes of behavior, working memory and cognition. In animal models, cotinine was demonstrated to ameliorate anxiety and to have antipsychotic and antidepressant properties [5-7].

In preclinical studies,it has been shown that acute or chronic nicotine treatments induce an antidepressant effect in the experimental animal, as well as improve performance on attention and memory tasks.

The aim of this study was to investigate comparatively the antidepressant and anxiolytic effects of cotinine and nicotine in mice. Imipramine was used as a reference for the antidepressant activity.

\section{Experimental part}

Materials and methods

Animals used in experiments

In the present research, 40 healthy NMRI mice, of several weeks old and weigh of $30 \pm 2 \mathrm{~g}$ have been used. The animals were sheltered in transparent cages made of plexiglass, with access to water and food ad libitum. The cages were placed in a room with exposure to the artificial light, in cycles of $12 \mathrm{~h}$ a day, 6 h.A.M. and 6 h. P.M., in constant conditions of temperature and humidity.

Researches on animals used in experiments have been done according to the Directive 2010/63/UE on Sept. 22. 2010 and Law nr.43/2014, concerning the protection of animals used for experimental and scientific purposes.

\section{Substances}

The animals used in experiments were divided into four groups, having uniform locomotor activity. So, the mice in each group were weighed once in two days and were administered the following substances within 14 days:

-The controlgroup ( $n=12)$ : distilled water $0.1 \mathrm{~mL} / 10 \mathrm{~g}$ body, per os;

-The reference group $(n=12)$ : imipramine solution 25 $\mathrm{mg} / \mathrm{kg}$ body per Os;

-The nicotine group ( $n=12)$ : nicotine solution $0.5 \mathrm{mg} /$ kg body per os;

-The cotinine group $(n=12)$ : cotinine solution $5 \mathrm{mg} / \mathrm{kg}$ bodyper os.

The substances used for preparing the solutions have been provided by Sigma-Aldrich.

Behavioural tests

A series of behavioural tests were made in order to evaluate and compare the psychotropic effects induced by the administration of nicotine and its metabolite, cotinine. The animals used in experiments were taken to 
the testing room to get used to the conditions, one hour before the experiments, at the temperature of $19-22^{\circ} \mathrm{C}$ and constant light. All the tests on mice took place one hour after the administration of the substances.

\section{The locomotor activity}

The determination of the locomotor activity of the mice took place in different moments of the experiment. First, this had been quantified before the four groups were divided, being necessary for uniform distribution of the miceaccording to their locomotor activity. Also, the locomotor activity was determined in the days 1,7 , and 14 of the experiment, at the same time with the other tests, with the aim to evaluate the effects of imipramine, nicotine and cotinine on horizontal and vertical movements, and to identify the possible false positive or false negative of antidepressant and anxiolytic results. The locomotor activity was evaluated by using a special cage made of plexiglass (sizes: $40 \mathrm{~cm}$ per $40 \mathrm{~cm}$ ), equipped with sensors (Activity Cage, Ugo Basile, Italy). In this case, the number of movements was registered for five minutes for each animal, the cage being cleaned after every test.

\section{The antidepressant activity}

The antidepressant effect of the active substances may be highlighted with rodents by using two experimental classical models, i.e. the test of the forced swim test (FST) and the tail suspension test (TST) [9].

\section{The forced swim test}

The evaluation of the acute antidepressant effect of the substances to be tested was performed on the first day of the administration by using the forced swim test. The experiment lasted for 6 minutes, when the animal was let to swim free in the water. In the first two minutes of the test, the mice were left in the tank to get used to the water, followed by other four minutes to time their immobilization. The reduced time of immobilization corresponds to an antidepressant action of the psychotropic substances [1013].

\section{The tail suspension test}

This experimental model is based on the same principle as the previous one and it was used to determine the subacute antidepressant effect, after 7 days of administration, respectively subchronic, after 14 days of administration. As there is no need of an accommodation period of time in this experimental model, the time of immobilization was determined within the 6 minute test [14].

\section{The anxiolytic action}

An experimental model often used to evaluate the anxiolytic effect of the biologic active substances is the elevated plus maze [15]. The administered substance action on the mice anxiety was determined on the 15-th day of the experiment. The tested animals were placed in the centre of the labyrinth and were left free to explore it for exactly $5 \mathrm{~min}$. Within the $5 \mathrm{~min}$, several parameters were monitored: the time spent in the open arms, in the closed ones and in the centre of the labyrinth, and also, the total number of entries in the two types of arms. The time spent in the open arms is correlated with the anxiolytic effect of the tested substances[16-17].

\section{The statistic analysis}

The collected data of the experiments were analyzed using the GraphPad 5 and Microsoft Excel 2006 statistic analysis programmes. The data distribution type was determined by using d'Agnostino \& Pearson test. The evaluation of the statistic significance of the results was done by using the parametric (T-student, ANOVA) and nonparametric (Mann-Whitney, Wilcoxon, Kruskal-Wallis) tests. The obtained graphics represent either the average of the group + the standard deviation, or the percentage effect, caused by the administered substance, compared to the controlgroup.

\section{Results and discussions}

\section{Selection and group forming}

The four groups were made-up one day before the first testing day. Thus, it was determined the locomotor activity of the 50 mice. Following the results, the animals to be tested were redistributed in 4 groups of 12 mice each. Two mice were eliminated because of their extreme high and low initial motor activity values.

\section{The body weight}

Regarding the body weight of the mice, we noticed a slight increase during the two weeks, this being the situation for all the 4 groups. Thus, as regards the variation of the body weight, we did not notice any significant differences among the groups.

\section{The locomotor activity}

The locomotor activity of the animals to be tested was determined after the acute (on the first day), subacute (day 7) and subchronic (day 14) administration, in parallel with the antidepressant effect.

On the first testing day, there were noticed some slight differences among the groups, regarding the number of the horizontal movements. Concerning the vertical ones, the differences were higher in the case of the group treated with imipramine and the one treated with nicotine which caused the decrease of the motor activity by $33 \%$, respectively $16 \%$ (data not shown). However, these differences did not have any statistic significance ( $p>0.05$, t-Student).

On the 7-th day, there were registered $15 \%$ increase for the horizontal movements and 55\% for the vertical movements of the group treated with imipramine. Also, there were noticed $49 \%$ increase of the number of movements for the group treated with cotinine. Therefore, the administration of the imipramine and cotinine caused an obvious growth of the mice's motor activity after the subacute treatment, but without any statistic significance ( $p>0.05$, t-Student) (fig. 2a). After the 14 day treatment, nicotine reduced the vertical motor activity with $25 \%$, and cotinine reduced the number of movements with $10 \%$, but nor these differences were statistically significant $(p>0.05$, Mann-Whitney, t-Student) (fig. 2b).

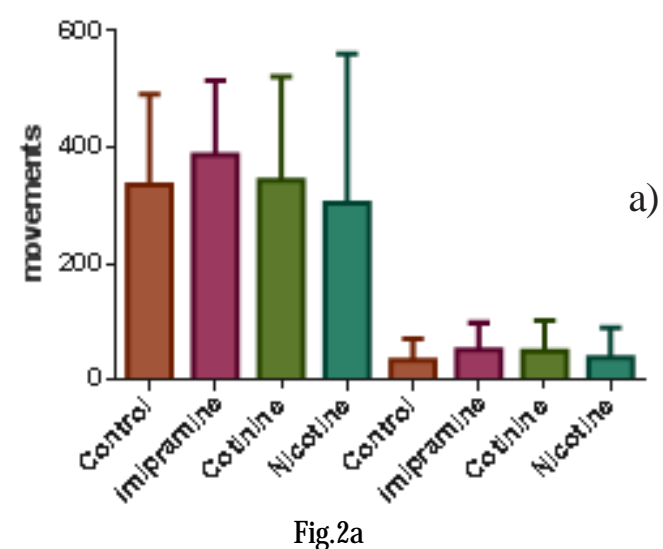




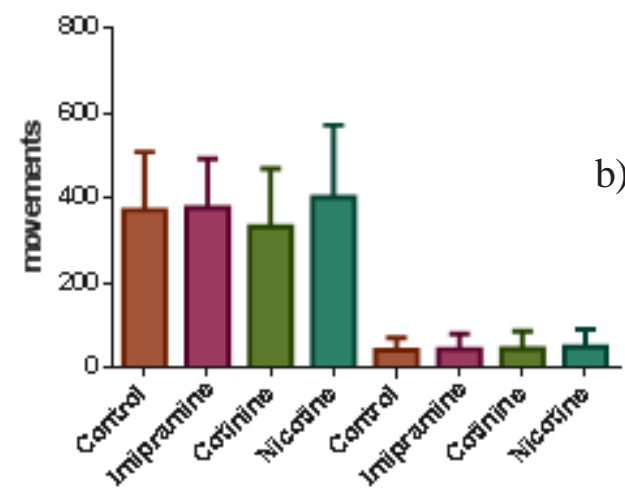

Fig.2. The effects exerted by nicotine, cotinine and imipramine on the locomotor activity in mice after 7 days (a.) and 14 days (b.) treatment. Horizontal movements -columns 1-4; vertical movements - columns 5-8

Concerning the variation of the motor activity during the treatment, it was found out that, in the case of the group treated with imipramine, there is a relatively constant decrease of the motor activity starting from day 1 to day 14 of the experiment, both in the case of the horizontal and the vertical movements. For the controlgroup and the one treated with nicotine, it was noticed a decrease of the motor activity on day 7 , followed by a growth on day 14 . In the case of the group treated with cotinine, itwas registered an important decrease of the motor activity on day 7 , compared to the first day of the experiment $(p<0.01$, $t-$ Student), followed by a new decrease after the 14 day treatment.

\section{The forced swim test}

No substance reduced the time of the mice immobilization while doing the forced swim test in the first day of the experiment.The lack of the antidepressant effect of imipramine after one administration may be explained by its indirect mechanism of action, being necessary several days of administration to notice an obvious effect.

\section{The tail suspension test}

The antidepressant effect after the subacute and subchronic administration was evaluated on day 7 , respectively day 14 , using the tail suspension test. After 7 days, both imipramine and cotinine produced antidepressant comparable effects, statistically significant $(p<0.05$, t-Student), with a $31 \%$ decrease of the immobilization time, respectively $24 \%$ (fig. $3 a$ ). The nicotine caused a growth of the immobilization time, being statistically insignificant.

The antidepressant effect of cotinine was not obvious after 14 days of treatment (fig. 3b), a possible cause being the reduced motor activity, which can influence the immobilization time within the experimental models for evaluation the antidepressant action. In the case of the imipramine it was noticed a decrease of the immobilization time compared to the controlgroup with 34\%.Nicotine did not significantly influenced the immobilization time.

The elevated plus mazetest

The last stage of the experiment concluded the evaluation of the anxiolytic effect of the administered substances, using the test of the elevated plus maze. In the case of imipramine, there were noticed an increase of the time spent in the closedarms by $20 \%$, compared to the controlgroup ( $p<0.05$, Mann-Whitney), a decrease of the time spent in the open arms by $64 \%$, a decrease of entries in open arms by $88 \%(p<0.05$, Mann-Whitney) and a

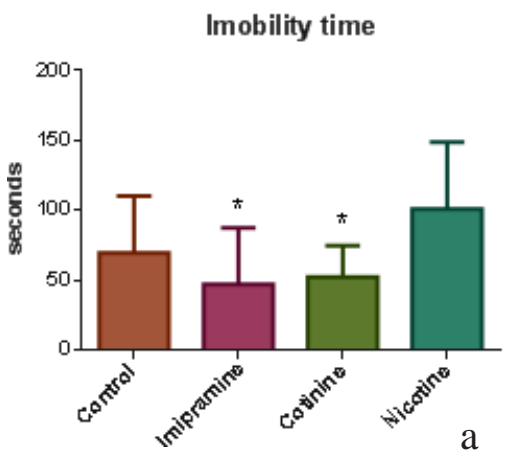

Imobility time

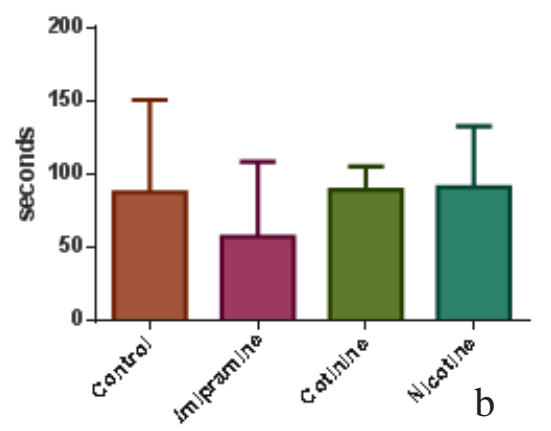

Fig. 3. The antidepressant activity of nicotine, cotinine and imipramine in mice after 7 days (a.) and 14 days (b.) treatment. The tail suspension test has been used for the evaluation of the antidepressant activity

decrease of the time spent in the centre of the labyrinth by $50 \%$ ( $p<0.05$, t-Student) (fig. $4 a, b, c)$. These results sum up an important anxiogenic effect, being a predictable pharmacological action, taking into account its mechanism ofaction. The nicotine administration caused, on day 15 an anxiolytic effect on mice, noticing an important growth by $129 \%$ of the time spent in the open arms ( $p<0.05$, t-Student) and the increase of the entries in open arms by $52 \%$ (fig. $4 a, b$ ). In the case of cotinine, there were no significant effects on the level of anxiety of the tested animals (fig. $4 a, b, c$ ).
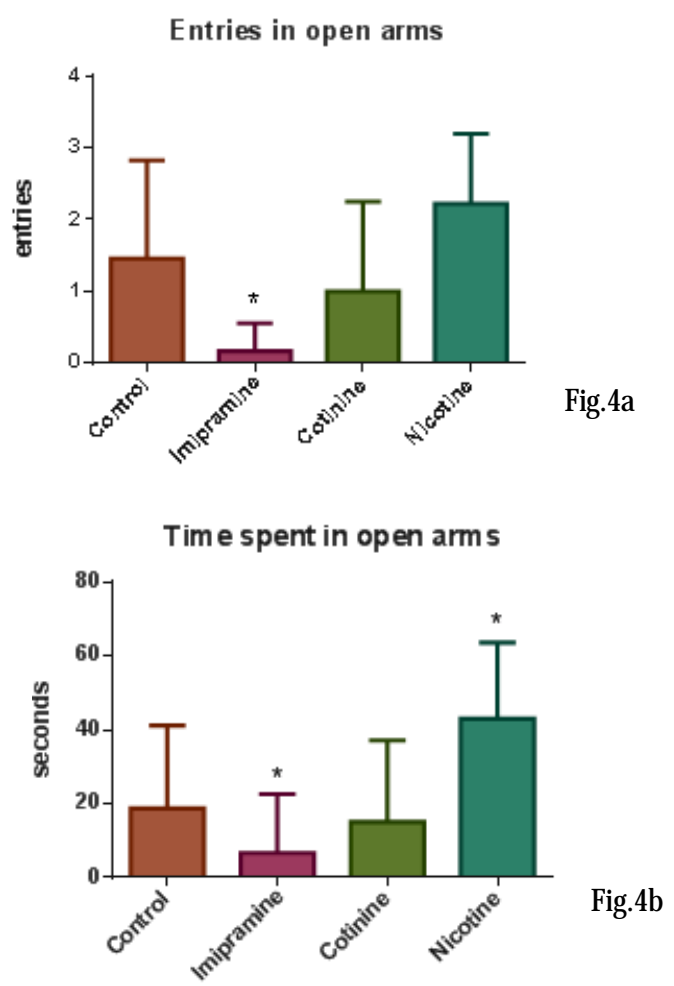


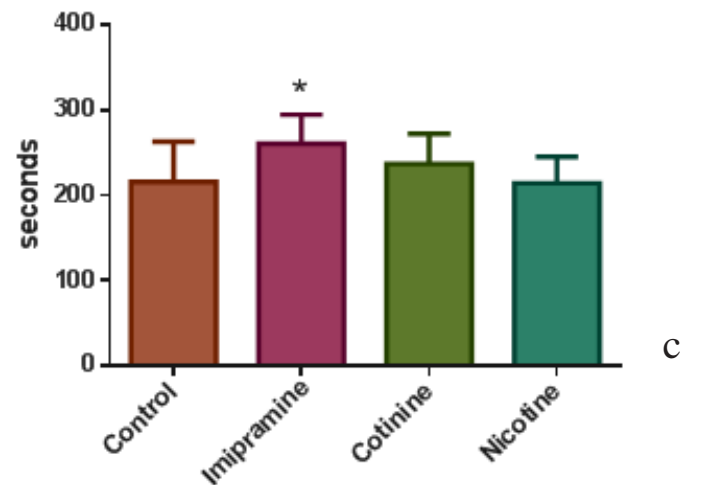

Fig. 4 ine anxiolytıc activity of nıcotıne, cotınıne and ımıpramine in mice after 14 days treatment. The elevated plus maze test has been used for the evaluation of the anxiolytic activity as entries in open arms (a), time spent in open arms (b.) and time spent in closed arms (c.)

\section{Conclusions}

Both nicotine and its metabolite, cotinine caused psychoactive effects on mice, within the behavioural tests. In the case of the tail suspension test, cotinine caused an antidepressant effect comparable to imipramine after 7 days of administration, and nicotine induced an anxiolytic effect, determined on day 15 of the experiment using the elevated plus maze. However, these results are not totally in accordance with other reports of the literature and further studies are required to clarify the treatment regimenand mechanisms contributing to psychotropic effects.

\section{References}

1.TIZABI Y, HAUSER S.R., TYLER K.Y., Progress in Neuropsychopharmacology and Biological Psychiatry, 34, 2009, p.62. 2.MORAN V.E.,Frontiers in Pharmacology, 3, 2012, p.173.
3.TERRY A.V. JR, HERNANDEZ C.M., HOHNADEL E.J., BOUCHARD K.P., BUCCAFUSCO J.J ., CNS Drug Reviews banner, 11, 2005, p.229. 4.VLASCEANU A.M., PETRARU C., BACONI D., GHICA M., ARSENE A., POPA L., NICOLAE A., DRAGOI C.M., PAVALACHE G., Farmacia, 6 , 2015, p. 349.

5.ECHEVERRIA V, GRIZZELL J.A., BARRETO G.E., Current Pharmaceutical Design, 22, 2016, p.1324.

6.GRIZZELL J .A., ECHEVERRIA V.,Neurochemical Research, 40, 2015, p. 2032.

7.GRIZZELL J.A., MULLINS M., IARKOV A., ROHANI A., CHARRY L.C., ECHEVERRIA V., Behavioral Neuroscience., 128, 2014, p.713.

8.VLASCEANU A. M., BACONI D.L., CIOBANU A.M., CONSTANTIN V.D., PLES L., BALALAU C., STAN M., J ournal of Mind and Medical Sciences, 5, 2018, p.15.

9.KEDZIERSKAE., WACH I., Current Issues in Pharmacy and Medical Sciences, 2016, 29, p.61.

10.CAN A., DAO D.T., ARAD M., TERRILLION C.E., PIANTADOSI S.C., GOULD T.D.,J ournal of Visualized Experiments, 59,2012a, p.3638.

11.YANKELEVITCH-YAHAV R., FRANKO M., HULY A., DORON R., J ournal of Visualized Experiments, 97, 2015, p. 52587.

12.NEGRES S., ZBARCEA C.E., ARSENE A., CHIRITA C., BUZESCU A., VELESCU B.S., STEFANESCU E., SEREMET O.C., NICOLESCU F., Farmacia, 61, 2013,p.1102.

13.CHIRITA C., CIOROIANU D.M., CHIRITA I.C., NEGRES S., MARIAN B., ZBARCEA C.E.,Farmacia, 64, 2016, p.61.

14.CAN A., DAO D.T., TERRILLION C.E., PIANTADOSI S.C., BHAT S., GOULD T.D., Journal of Visualized Experiments, 59, 2012b, p.3769.

15.RIPOLL ROZISKY J., LASTEG., MEDEIROS L., SOUZA SANTOS V., ADACHI L.N., MACEDO I., CALMOW., TORRESI.L., 2013. British J ournal of Medicine \&Medical Research, 4, 2013, p. 351.

16.KOMADA M., TAKAO K., MIYAKAWA T., Journal of Visualized Experiments, 22, 2008, p.1088.

17.WALF A.A., FRYE C.A., Nature Protocols,2, 2007, p.322.

18. CHIVU, O.R., MEDERLE, O., SEMENESCU, A., et. all., Rev. Chim. (Bucharest), 69, no. 4, 2018, p. 575

Manuscript received: 12.09 .2018 